\title{
Research on complex integrated energy planning and operation optimization
}

\author{
Zhou Wen ${ }^{1}$, Liang Meng ${ }^{1}$, Zhengfu Yang ${ }^{2}$, Zhibin Liu $^{3, *}$, and Yajing Liu ${ }^{3}$ \\ ${ }^{1}$ Electric Power Research Institute of Hebei Electric Power Co., Ltd, 050000 Shijiazhuang, China \\ ${ }^{2}$ State Grid xiong'an Digital Technology Co., Ltd, 071000 Baoding, China \\ ${ }^{3}$ School of Electronic and Control Engineering, North China Institute of Aerospace Engineering \\ 065000 Langfang, China
}

\begin{abstract}
The safe and stable operation of the energy system is the top priority of the world in the industrial field. The energy integrated system optimizes the system through multiple channels and cascade utilization of energy, which greatly improves the utilization rate of energy and provides a convenient way for the development of low-carbon society. In this paper, the composite integrated energy system model is constructed through the analysis of the structure of the integrated energy system. On this basis, a coordinated optimal scheduling method for integrated energy system with multiple energy stations is proposed, which takes the system operation economy as the goal. The case simulation results show that the coordinated operation of energy stations can greatly improve the stability and economy of the hybrid integrated energy system.
\end{abstract}

\section{Introduction}

The existing literature separates optimization scheduling from the configuration optimization. Reference [1-2] carryout comprehensive modelling of electric power, natural gas and thermal system, analyses the model of energy network, and carries out energy flow analysis on this basis; Reference [3] adopts the multi-criterion partial pressure method to analyse the micro-cooling and heating power systems under different climatic conditions;

In reference [4-5], a multi-user optimal configuration model with energy storage is established aiming at configuration economy. Reference [6-8] research on home energy efficiency management strategies based on distributed photos tatting power stations and energy storage systems.

Based on the concept of complex integrated energy, it will interconnect all kinds of new energy sources and optimize the allocation and operation of resources, to realize the complementation of integrated energy, and then to maximize the benefits in real life, compared with existing literature, considering the operation economy, environmental protection and energy saving of the scheme, in order to achieve energy allocation and operation optimization.

\footnotetext{
*Corresponding author:94190859@qqq.com
} 


\section{Introduction to the complementary coordination program for integrated energy systems}

The complex integrated energy system is composed of several distributed energy stations and load zones. The "horizontal multi-purpose complementation" in the energy Internet refers to the complementary coordination among various energy resources in distributed energy stations, highlighting the "substitution". In order to improve the utilization rate of resources, the "source-network-load-storage" coordinated development concept is adopted in the process of distributed energy scheduling. Therefore, the coordinated development strategy of source-net-load-storage is put forward. Source-net-load complementary coordination: first of all, introducing demand-side response on the load side and using direct load means to reduce load tracking fan and photo voltaic output, the load cannot be reduced during the peak period of renewable energy output.

\section{Mathematical model of integrated energy system optimization planning}

\subsection{Power network model}

We first assume that the rated voltage between each energy station, then the transmission loss between the two energy stations is

$$
\begin{gathered}
\mathrm{P}_{\text {Lloss }}^{\mathrm{e}}(\mathrm{t})=\mathrm{I}_{\mathrm{L} 1}^{2} 2(\mathrm{t}) \times \mathrm{R}_{112}(\mathrm{t}) \\
I_{L 12}(t)=P_{L 12}(\mathrm{t}) / \mathrm{U}_{\mathrm{N}}
\end{gathered}
$$

The formula: $P_{\text {Lloss }}^{\mathrm{e}}(t)$ is the transmission loss between two energy stations; $I_{L 12}^{2}(t)$ is the current of each line between the energy stations; the $P_{L 12}(t)$ is the resistance of each line between the energy stations; and the $U_{N}$ is the rated voltage between the energy stations.

\subsection{CHP unit model}

At present, in the modeling of integrated energy system, the equivalent treatment of each energy station is carried out. As the core equipment of the integrated energy system, the CHP unit uses the load end of the natural gas system and the source end of the power generation system to cool and heat the whole energy of the system is connected.

$$
\begin{gathered}
\max F=-f_{1}+f_{2} \\
P_{C H P . \text { e.t }}+\mathrm{P}_{\text {grid.e.t }}+\mathrm{P}_{\text {new.t }}=\mathrm{L}_{\text {e.t }}-\mathrm{L}_{\text {cut.e.t }}+\mathrm{P}_{\text {BT.e.t }}+\mathrm{P}_{\text {HP.e.t }} \\
P_{C H P . h . t}+P_{G B . h . t}+P_{\text {grid.h.t }}=L_{\text {h.t }}+P_{B T . h . t}+P_{A C . h . t}
\end{gathered}
$$




$$
\begin{gathered}
P_{A C . C . t}=L_{c . t} \\
\sum_{i=1}^{n 1} \text { Pi.e.max }+ \text { Pgrid.e. } \max >\max (L \mathrm{e}-\text { Pnew })(1+10 \%) \\
\sum_{i=1}^{n 2} \text { Pi.h. } \max +\text { Pgrid.h. } \max >\text { Lh. } \max (1+10 \%)
\end{gathered}
$$

In the formula, $f_{1}$ allocation costs for energy systems; $f_{2}$ for the comprehensive benefits of energy system operation; $P_{C H P . \text {.e. }}$ is the generation power and heat generation power of CHP system in the period. $P_{j \text {.grid.e.max }}, P_{\mathrm{j} \text {.grid.max }}$ is the upper limit of power line and heat transmission pipeline energy station.

\subsection{Constraints}

(1) Energy balance constraints within energy stations

Each of the two energy stations in the regional integrated energy system needs to meet the constraints of the balance of electric energy, heat energy and cold energy. It is now expressed as formula (10)-(12).

$$
\begin{gathered}
\sum_{q 1=1}^{c h p} P_{C H P . q 1}^{c}(\mathrm{t})+P_{\text {load }}^{h}(t)-P^{c h a}(\mathrm{t})+P^{d i s}{ }_{C S}(t)=P_{\text {load }}^{c}(\mathrm{t}) \\
T_{T S B}^{h}(t)-P^{c h a}{ }_{H S}(t)+P^{d i s}{ }_{H S}(t)=P_{\text {load }}^{h}(t) \\
\min C=C_{f}+C_{\mathrm{e}}+C_{w}
\end{gathered}
$$

$P_{\text {load }}^{h}(t)$ is the electric, heat and cooling loads of the regional integrated energy system, $P^{c h a}(t)$ is the number of CHP units and gas turbines in the $t$ period, and the predicted power generation of wind power and photovoltaic in the t period. $T_{T S B}^{h}(t)$ is energy station 1 to energy station 2 . And $P_{\text {load }}^{\mathrm{h}}(t)$ is negative when the energy station 2 conveys electric power and thermal power to the energy station 1 .

$$
\begin{gathered}
0 \leq P_{\text {huy }}^{\mathrm{e}}(t) \leq P_{\text {buy max }}^{\mathrm{e}} \\
0 \leq P_{\text {mell }}^{\mathrm{e}}(\mathrm{t}) \leq \mathrm{P}_{\text {sell.max }}^{\mathrm{e}}
\end{gathered}
$$

The $P_{h u y}^{\mathrm{e}}(t)$ and $P_{b u y}^{\mathrm{e}}(t)$ are the maximum allowable power to buy and sell electricity respectively.

(2) CHP unit start-stop time constraint

$$
\left(T^{o n}{ }_{C H P}-T_{C H P}^{U}\right)\left(U_{C H P}(\mathrm{t}-1)-U_{C H P}(t)\right) \geq 0
$$




$$
\left(T^{\text {off }}{ }_{C H P}-T_{C H P}^{D}\right)\left(U_{C H P}(t)-U_{C H P}(t-1)\right) \geq 0
$$

The $U_{C H P}(\mathrm{t})$ is the starting and stopping state of the CHP unit in the t period; the $T^{D}{ }_{C H P}, \quad T^{o f f} C_{H P}$ is the continuous start-up and shutdown time of the unit before the t period; and the minimum continuous start-up and shutdown time required by the CHP unit respectively.

(3) Constraints on climbing rate of CHP units

$$
P_{C H P}^{\text {down }} \leq\left(\mathrm{P}_{\text {CHP }}^{\mathrm{e}}(\mathrm{t})-\mathrm{P}_{\text {CHP }}^{\mathrm{e}}(\mathrm{t}-1)\right) \leq \mathrm{P}_{C H P}^{\text {up }}
$$

The $P^{d o w n}{ }_{C H P}$ and $P_{C H P}^{u p}$ are the maximum downhill rate and the maximum climbing rate of the electric output force of the CHP unit, respectively.

\section{Case study}

The integrated energy system load and renewable energy processing forecast data are shown in Figure 1. Energy Station 2 is equipped with a gas boiler with limited capacity to generate heat energy at the peak of heat load.

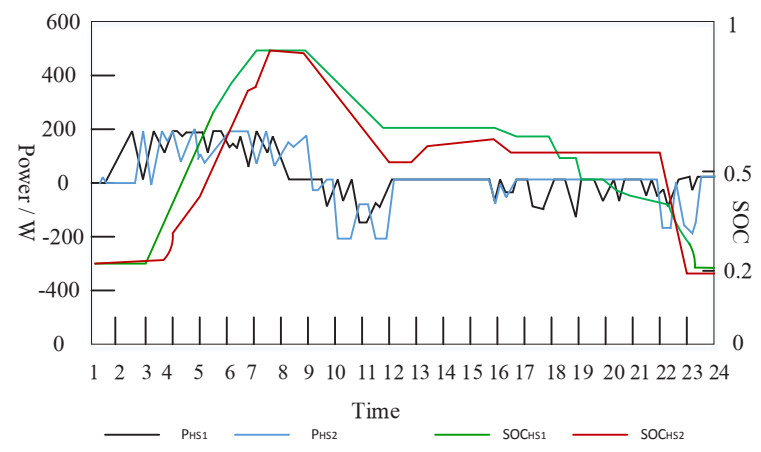

Fig. 1. Operation of thermal energy storage.

\begin{tabular}{|c|c|c|c|c|c|}
\hline \multirow{2}{*}{\multicolumn{2}{|c|}{ Cost }} & \multirow{3}{*}{$\begin{array}{l}\text { Mode1 } \\
2610\end{array}$} & \multicolumn{2}{|c|}{ Mode 2} & \multirow{3}{*}{$\begin{array}{l}\text { Mode } 3 \\
14355\end{array}$} \\
\hline & & & \multirow{2}{*}{$\begin{array}{c}\begin{array}{c}\text { Energy } \\
\text { station1 } 1\end{array} \\
2628\end{array}$} & \multirow{2}{*}{$\begin{array}{c}\begin{array}{c}\text { Energy } \\
\text { station } 2\end{array} \\
834\end{array}$} & \\
\hline \multirow[b]{3}{*}{ Electricity } & $\begin{array}{l}\text { Purchase of } \\
\text { electricity }\end{array}$ & & & & \\
\hline & Sell electricity & 1 & 304 & 306 & 0 \\
\hline & Total electricity & 2609 & 2324 & 528 & 14355 \\
\hline \multicolumn{2}{|c|}{ Gas costs } & 15268 & 8739 & 6980 & 8689 \\
\hline \multicolumn{2}{|c|}{ Start-up charges } & 0 & 0 & 0 & 0 \\
\hline \multicolumn{2}{|c|}{ Maintenance } & 2261 & 1326 & 995 & 0 \\
\hline \multicolumn{2}{|c|}{ Total costs } & 20138 & \multicolumn{2}{|c|}{20892} & 23044 \\
\hline
\end{tabular}

Table 1. Comparison of operating costs of 3 operating modes.

In order to verify the economic type of energy system station coordination and optimal operation method, two ways can be set up. It can be seen from Table 1 that the energy supply cost of mode 3 is the highest, that of mode 1 is $12.6 \%$ higher than that of mode 3 , 
and that of mode 1 is $3.6 \%$ higher than that of mode 2 . Among mode 3, the purchase cost is the most, accounting for $75.8 \%$ of the total operating cost, while the purchase cost is only 13.0.

\section{Conclusion}

This paper puts forward a cooperative optimization strategy of energy station of integrated energy system with the goal of system operation economy. Through case analysis, it is verified that the coordinated optimal operation of complex integrated energy station can greatly improve the economic and environmental protection of terminal energy supply.

Science and Technology Project of State Grid Corporation of China, kjcb-2020-44. Research on key technologies of energy efficiency assessment and global optimization of composite integrated energy systems.

\section{References}

1. Ri fkin,J.(2011) The Third Industrial Revolution:How Lateral Power Is Transforming Energy,Economy, and the World.Pal grave MacMillan,New York,46-48, (2011).

2. Antislavery,P.,Bryan,K.and Tihomir,M.(2009) Smart Girds BETTER With Integrated System.2009 IEEE Electrial Power \& Energy Conference(EPEC),Montreal,QC,22-23 October, 1-8 (2009)

3. Masood,E.and Ali,K.(2013)Sizing the Prime MOVER OF A residential MicroCombined Cooling Heating and Power(CCHP)System by Multi-Criteria Sizing Method for Different Climates.Energy,54,291-301.

4. Yokoyama,R.and Ito,K.(2004) Optimal Design Of Gas Turbine Co generation Plants in Consideration of Discreteness of Equipment.Capacities.Proceedings of ASME Turbo Expo 2004:Power for Land,Sea, and AIR,Vienna,14-17 (2004).

5. Wang Sn EA al.2016 A Coordinated Charging Control Strategy FOR Electric Vehicles Char aging Load in Residential Area(Automation of Electric Power Systems vol 40)pp71-77

6. GAO Lin,WANG Chintz,ZOU Jingalong,et al.Research on home energy efficiency management strategy based on distributed photo voltaic power station and energy storage system[J].Power Demand Side Management, 19(2):20-24, (2017)

7. LOPESJ A P et al.2011 Integration of electric vehicles in the electric power system(Price endings of the CSEE vol 99),PP 168-183

8. LIU X,JENKINS N,WU J,et al.Combined analysis of electricity and heat networks[J] 